Article

\title{
Impact of Five Succinate Dehydrogenase Inhibitors on DON Biosynthesis of Fusarium asiaticum, Causing Fusarium Head Blight in Wheat
}

\author{
Chao Xu ${ }^{1}$, Meixia Li ${ }^{1}$, Zehua Zhou ${ }^{1}$, Jiaosheng $\mathrm{Li}^{1}{ }^{1}$, Dongming Chen ${ }^{1}$, Yabing Duan ${ }^{1,2, * \mathbb{D}}$ and \\ Mingguo Zhou 1,2,* \\ 1 College of Plant Protection, Nanjing Agricultural University, Nanjing 210095, China; \\ 2016102130@njau.edu.cn (C.X.); 2016102106@njau.edu.cn (M.L.); 2014202047@njau.edu.cn (Z.Z.); \\ 2016102114@njau.edu.cn (J.L.); 2016102131@njau.edu.cn (D.C.) \\ 2 State \& Local Joint Engineering Research Center of Green Pesticide Invention and Application, \\ Nanjing 210095, China \\ * Correspondence: dyb@njau.edu.cn (Y.D.); mgzhou@njau.edu.cn (M.Z.)
}

Received: 22 April 2019; Accepted: 6 May 2019; Published: 15 May 2019

check for updates

\begin{abstract}
Deoxynivalenol (DON) is a class of mycotoxin produced in cereal crops infected with Fusarium graminearum species complex (FGSC). In China, FGSC mainly includes Fusarium asiaticum and F. graminearum. DON belongs to the trichothecenes and poses a serious threat to the safety and health of humans and animals. Succinate dehydrogenase inhibitors (SDHIs) are a class of fungicides that act on succinate dehydrogenase and inhibit the respiration of pathogenic fungi. In this study, the fungicidal activities of five SDHIs, including fluopyram, flutolanil, boscalid, benzovindiflupyr, and fluxapyroxad, against FGSC were determined based on mycelial growth and spore germination inhibition methods. The five SDHIs exhibited better inhibitory activities in spore germination than mycelial growth. Fluopyram exhibited a higher inhibitory effect in mycelial growth and spore germination in comparison to the other four SDHIs. In addition, the biological characteristics of F. asiaticum as affected by the five SDHIs were determined. We found that these five SDHIs decreased DON, pyruvic acid and acetyl-CoA production, isocitrate dehydrogenase mitochondrial (ICDHm) and SDH activities, and NADH and ATP content of $F$. asiaticum but increased the citric acid content. In addition, TRI5 gene expression was inhibited, and the formation of toxisomes was disrupted by the five SDHIs, further confirming that SDHIs can decrease DON biosynthesis of F. asiaticum. Thus, we concluded that SDHIs may decrease DON biosynthesis of F. asiaticum by inhibiting glycolysis and the tricarboxylic acid (TCA) cycle. Overall, the findings from the study will provide important references for managing Fusarium head blight (FHB) caused by FGSC and reducing DON contamination in F. asiaticum-infected wheat grains.
\end{abstract}

Keywords: deoxynivalenol; Fusarium asiaticum; succinate dehydrogenase inhibitor; glycolysis; tricarboxylic acid cycle; toxisomes

Key Contribution: SDHIs can decrease DON biosynthesis in F. asiaticum and should be applied to control FHB in wheat caused by F. asiaticum.

\section{Introduction}

Fusarium head blight (FHB) is a devastating disease in wheat and other small grain cereals and is caused by Fusarium graminearum species complex (FGSC), including at least 16 distinct and cryptic species, and some species have specific geographical distributions [1,2]. In China, FGSC causing FHB is mainly composed of $F$. asiaticum and F. graminearum [3,4]. The disease can not only cause serious 
yield and quality losses in many wheat-growing regions, but also FHB pathogens can produce a series of trichothecene mycotoxins in FGSC-infected wheat grains, including deoxynivalenol (DON) and its acetylated derivatives ( $3 \mathrm{AcDON}, 15 \mathrm{AcDON}$ ) and nivalenol (NIV), thus posing a grave threat to the safety and health of humans and animals [5]. DON has been demonstrated to be the most common contamination associated with FGSC-infected wheat grains and can cause hematic and anorexic syndromes as well as neurotoxic and immunotoxic effects in mammals. Additionally, DON has also been reported as an important virulence factor of FGSC [6,7].

The control of FHB always depends on chemical fungicides. Previous studies have shown that the resistance of benzimidazole is already widespread in China, especially in eastern China, and that there is a high resistance risk of FGSC to phenamacril [8-10]. Accordingly, it is of great importance to discover and develop novel fungicides that exhibit inhibitory effects on the fungal growth and DON biosynthesis of FHB pathogens. Succinate dehydrogenase inhibitors (SDHIs) are a new class of chemical fungicides. Previous studies have demonstrated that SDHIs target enzyme complex II of the mitochondrial respiratory electron transport chain, namely succinate dehydrogenase (SDH) or succinate quinone reductase (SQR) in phytopathogenic fungi [11,12]. The enzyme complex II is also an important functional part of the tricarboxylic acid (TCA) cycle and is linked to mitochondrial respiratory electron transport chain for catalysis of the coupling reaction from succinic acid oxidation to fumaric acid and reduction from ubiquinone to ubiquinol. It includes four subunits: Flavoprotein (SdhA), iron-sulfur protein (SdhB), and two other integral membrane proteins (SdhC and SdhD) $[13,14]$. In terms of chemical structure, SDHIs contain an amide group (-CONH-). Most of the newly developed fungicides are based on the original reactive group as a backbone. At present, SDHIs have been widely applied for controlling many plant diseases [15-18]. However, SDHIs are rarely used to control FHB, especially in the control of DON production in wheat grains. In this study, the effects of five SDHIs, fluopyram, flutolanil, boscalid, benzovindiflupyr, and fluxapyroxad, in inhibiting mycelial growth, spore germination of FGSC, and DON biosynthesis of F. asiaticum were determined. This study also evaluated the expression of TRI5 gene, which is the DON biosynthesis-associated gene. In addition, the impacts of five SDHIs on DON biosynthesis-associated biological characteristics such as pyruvic acid, acetyl-CoA, ATP, citric acid and activities of several key enzymes were evaluated in vitro. Finally, the effect of these five SDHIs on toxisomes was investigated using a confocal laser scanning microscope.

\section{Results}

\subsection{Sensitivity of FGSC to Five Succinate Dehydrogenase Inhibitors}

In this study, the sensitivity tests of 13 FGSC strains to five SDHIs were performed based on mycelial growth and spore germination inhibition methods. For mycelial growth, the $\mathrm{EC}_{50}$ values of 13 FGSC strains to fluopyram ranged from 1.65 to $10.0 \mu \mathrm{g} / \mathrm{mL}$ (Table 1). Additionally, the $\mathrm{EC}_{50}$ values of 13 FGSC strains to flutolanil, boscalid, benzovindiflupyr, and fluxapyroxad were higher than $100 \mu \mathrm{g} / \mathrm{mL}$. This suggested that fluopyram exhibits a better inhibitory effect in mycelial growth of FGSC compared to the other four SDHIs. For spore germination, the $\mathrm{EC}_{50}$ values ranged from 2.32 to $4.24 \mu \mathrm{g} / \mathrm{mL}$ for flutolanil, 1.19 to $3.06 \mu \mathrm{g} / \mathrm{mL}$ for boscalid, 1.79 to $2.98 \mu \mathrm{g} / \mathrm{mL}$ for benzovindiflupyr, 2.08 to $3.99 \mu \mathrm{g} / \mathrm{mL}$ for fluxapyroxad, and 0.39 to $0.74 \mu \mathrm{g} / \mathrm{mL}$ for fluopyram, respectively (Table 2). Fluopyram also exhibited a better inhibitory activity in spore germination than the other four SDHIs. The results suggested that the five SDHIs exhibited a better inhibitory effect on spore germination than mycelial growth of FGSC. 
Table 1. Sensitivity of Fusarium graminearum species complex (FGSC) to five succinate dehydrogenase inhibitors (SDHIs) fungicides based on mycelial growth.

\begin{tabular}{|c|c|c|c|c|c|c|c|c|c|c|c|c|c|}
\hline \multirow{2}{*}{ Fungicide } & \multicolumn{13}{|c|}{$\mathrm{EC}_{50}(\mu \mathrm{g} / \mathrm{mL})^{\mathrm{a}}$} \\
\hline & 2021 & BM-1 & BM-4 & BM-13 & BM-14 & BM-17 & BM-20 & BM-2 & BM-3 & BM-5 & BM-7 & BM-9 & BM-10 \\
\hline Fluopyram & $10.00 \pm 1.22$ & $9.29 \pm 0.32$ & $8.83 \pm 0.35$ & $1.65 \pm 0.17$ & $9.68 \pm 0.40$ & $7.79 \pm 0.41$ & $2.29 \pm 0.26$ & $6.65 \pm 0.38$ & $2.25 \pm 0.31$ & $9.65 \pm 0.02$ & $5.19 \pm 0.23$ & $6.32 \pm 0.30$ & $7.54 \pm 0.20$ \\
\hline Flutolanil & $>100$ & $>100$ & $>100$ & $>100$ & $>100$ & $>100$ & $>100$ & $>100$ & $>100$ & $>100$ & $>100$ & $>100$ & $>100$ \\
\hline Boscalid & $>100$ & $>100$ & $>100$ & $>100$ & $>100$ & $>100$ & $>100$ & $>100$ & $>100$ & $>100$ & $>100$ & $>100$ & $>100$ \\
\hline Benzovindiflupyr & $>100$ & $>100$ & $>100$ & $>100$ & $>100$ & $>100$ & $>100$ & $>100$ & $>100$ & $>100$ & $>100$ & $>100$ & $>100$ \\
\hline Fluxapyroxad & $>100$ & $>100$ & $>100$ & $>100$ & $>100$ & $>100$ & $>100$ & $>100$ & $>100$ & $>100$ & $>100$ & $>100$ & $>100$ \\
\hline
\end{tabular}

a Values are the means \pm SEs of three replicate experiments.

Table 2. Sensitivity of FGSC to five SDHIs fungicides based on spore germination.

\begin{tabular}{|c|c|c|c|c|c|c|c|c|c|c|c|c|c|}
\hline \multirow{2}{*}{ Fungicide } & \multicolumn{13}{|c|}{$\mathrm{EC}_{50}(\mu \mathrm{g} / \mathrm{mL})^{\mathrm{a}}$} \\
\hline & 2021 & BM-1 & BM-4 & BM-13 & BM-14 & BM-17 & BM-20 & BM-2 & BM-3 & BM-5 & BM-7 & BM-9 & BM-10 \\
\hline Fluopyram & $0.54 \pm 0.11$ & $0.74 \pm 0.08$ & $0.66 \pm 0.08$ & $0.39 \pm 0.05$ & $0.67 \pm 0.06$ & $0.56 \pm 0.04$ & $0.56 \pm 0.06$ & $0.54 \pm 0.03$ & $0.52 \pm 0.05$ & $0.68 \pm 0.08$ & $0.54 \pm 0.05$ & $0.69 \pm 0.14$ & $0.61 \pm 0.03$ \\
\hline Flutolanil & $2.96 \pm 0.21$ & $3.23 \pm 0.06$ & $2.68 \pm 0.07$ & $2.47 \pm 0.04$ & $3.52 \pm 0.10$ & $3.01 \pm 0.04$ & $2.33 \pm 0.03$ & $2.84 \pm 0.01$ & $2.78 \pm 0.01$ & $4.24 \pm 0.05$ & $2.50 \pm 0.07$ & $2.99 \pm 0.07$ & $2.32 \pm 0.04$ \\
\hline Boscalid & $1.52 \pm 0.11$ & $1.78 \pm 0.08$ & $2.58 \pm 0.07$ & $1.19 \pm 0.05$ & $2.11 \pm 0.04$ & $2.09 \pm 0.03$ & $1.57 \pm 0.07$ & $2.07 \pm 0.03$ & $1.28 \pm 0.09$ & $2.41 \pm 0.10$ & $3.06 \pm 0.06$ & $2.37 \pm 0.06$ & $2.40 \pm 0.05$ \\
\hline Benzovindiflupyr & $1.79 \pm 0.08$ & $2.86 \pm 0.09$ & $2.43 \pm 0.06$ & $1.96 \pm 0.04$ & $2.02 \pm 0.07$ & $2.39 \pm 0.05$ & $2.20 \pm 0.03$ & $2.59 \pm 0.04$ & $2.03 \pm 0.03$ & $2.98 \pm 0.08$ & $2.15 \pm 0.03$ & $2.92 \pm 0.06$ & $2.74 \pm 0.06$ \\
\hline Fluxapyroxad & $3.16 \pm 0.05$ & $2.95 \pm 0.05$ & $3.00 \pm 0.04$ & $2.30 \pm 0.05$ & $3.72 \pm 0.06$ & $3.99 \pm 0.04$ & $2.08 \pm 0.04$ & $3.19 \pm 0.05$ & $3.35 \pm 0.06$ & $3.78 \pm 0.06$ & $3.36 \pm 0.06$ & $3.15 \pm 0.02$ & $3.27 \pm 0.05$ \\
\hline
\end{tabular}

${ }^{\mathrm{a}}$ Values are the means \pm SEs of three replicate experiments. 


\subsection{DON Production and TRI5 Gene Expression}

To explore the inhibitory effect of SDHIs in DON biosynthesis, DON production and TRI5 gene expression of F. asiaticum strain 2021 treated with SDHIs were determined. All fungicide treatments significantly decreased the DON content. Under treatments of flutolanil, boscalid, fluxapyroxad, and benzovindiflupyr, the DON content of 2021 decreased $40-50 \%$, but decreased by approximately $70 \%$ under treatment of fluopyram (Figure 1A).

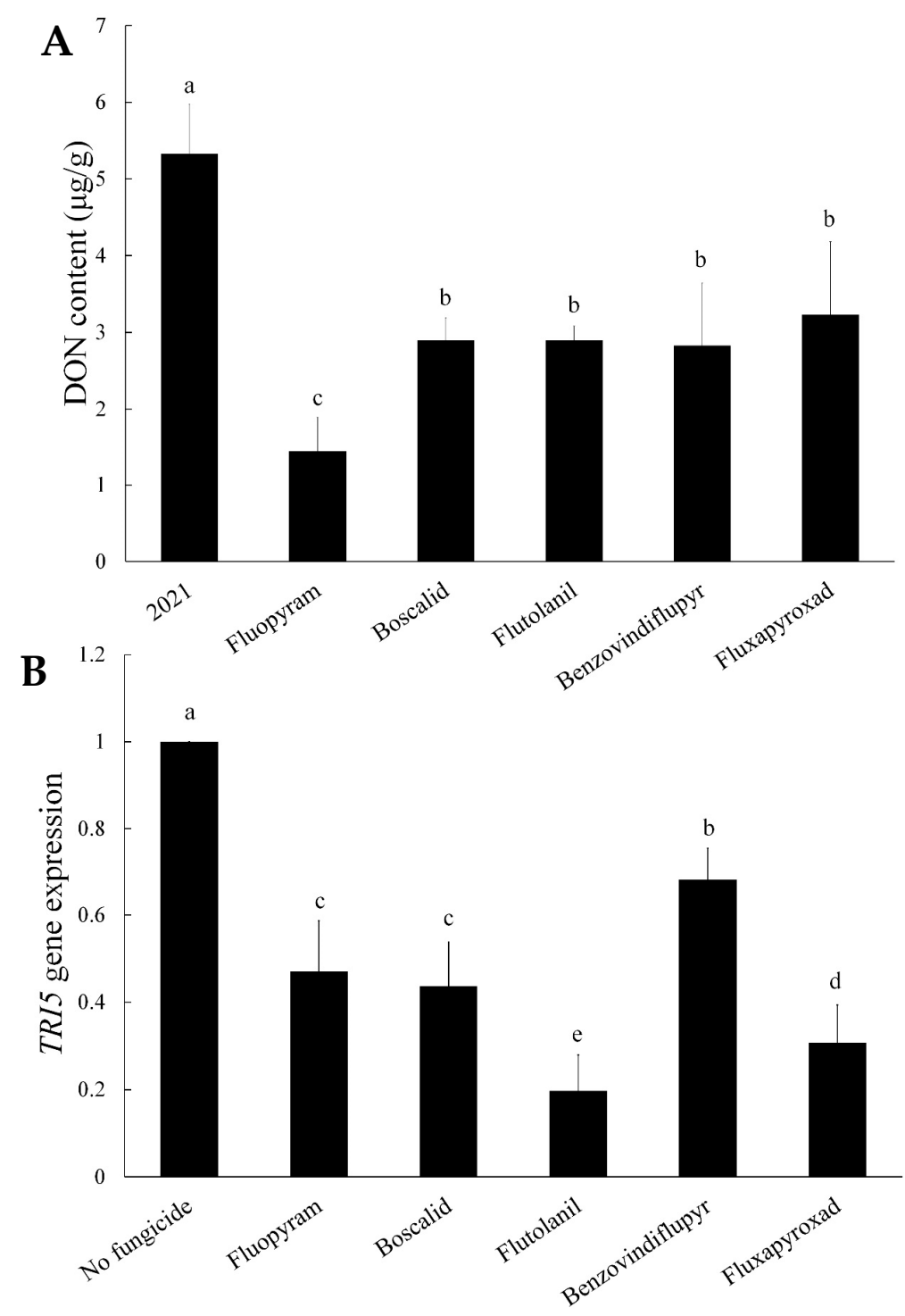

Figure 1. Effects of the five SDHIs in inhibiting deoxynivalenol (DON) production and TRI5 gene expression in F. asiaticum in vitro. (A) The amount of DON produced by the wild-type strain 2021 in GYEP as affected by the five SDHIs. (B) The relative expression of the TRI5 gene in the wild-type strain 2021 in GYEP as affected by the five SDHIs. The final concentrations were $0.54 \mu \mathrm{g} / \mathrm{mL}$ for fluopyram, $2.96 \mu \mathrm{g} / \mathrm{mL}$ for flutolanil, $1.52 \mu \mathrm{g} / \mathrm{mL}$ for boscalid, $1.79 \mu \mathrm{g} / \mathrm{mL}$ for benzovindiflupyr, and $3.16 \mu \mathrm{g} / \mathrm{mL}$ for fluxapyroxad, respectively. Values are means and standard errors of three replicates. Means with different letters are significantly different $(p<0.05$, ANOVA, LSD).

The TRI5 gene is a key gene for DON biosynthesis [19]. The transcriptional level of the TRI5 gene in the strains was assayed by qRT-PCR. The TRI5 gene was significantly down-regulated in the strain 2021 when treated with these five SDHIs (Figure 1B). Therefore, TRI5 expression indicated that SDHIs, especially fluopyram, can significantly reduce the biosynthesis of DON in F. asiaticum. 


\subsection{Pyruvic Acid and Acetyl-CoA Content}

Pyruvic acid and acetyl-CoA are the main precursors for DON biosynthesis $[20,21]$. The above described results indicated that SDHIs can effectively inhibit DON biosynthesis. To further reveal the relation between DON biosynthesis and pyruvic acid or acetyl-CoA, we determined the pyruvic acid and acetyl-CoA content under the same culture conditions as DON determination. The results showed that the pyruvic acid and acetyl-CoA content of the strain 2021 significantly decreased when treated with these five SDHIs (Figure 2). We concluded that SDHIs inhibit the DON biosynthesis of F. asiaticum by decreasing pyruvic acid and acetyl-CoA production.
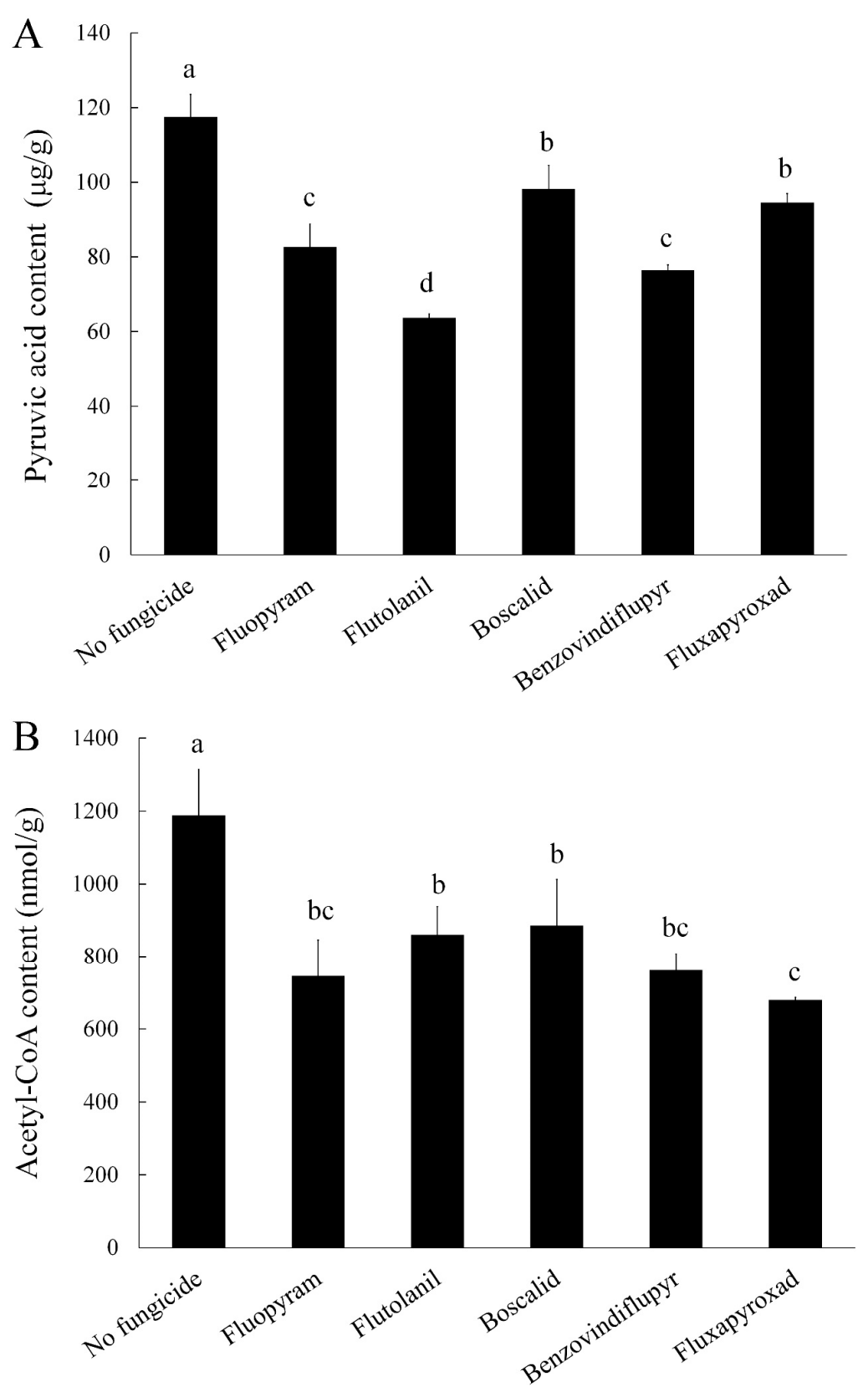

Figure 2. Impacts of the five SDHIs on pyruvic acid (A) and acetyl-CoA (B) production in the wild-type strain 2021. The final concentrations were $0.54 \mu \mathrm{g} / \mathrm{mL}$ for fluopyram, $2.96 \mu \mathrm{g} / \mathrm{mL}$ for flutolanil, $1.52 \mu \mathrm{g} / \mathrm{mL}$ for boscalid, $1.79 \mu \mathrm{g} / \mathrm{mL}$ for benzovindiflupyr, and $3.16 \mu \mathrm{g} / \mathrm{mL}$ for fluxapyroxad, respectively. Values are means and standard errors of three replicates. Means with different letters are significantly different $(p<0.05$, ANOVA, LSD). 


\subsection{The Relative Expression of Key Genes in the Glycolysis Pathway}

Pyruvic acid is mainly derived from the glycolysis pathway. We found that SDHIs can significantly inhibit the pyruvic acid content. Here, we determined the relative expression levels of three key genes hexokinase (FGSG_00500), 6-phosphate fructokinase (FGSG_09456), and pyruvate kinase (FGSG_07528) in the glycolysis pathway. We found that fluopyram, flutolanil, boscalid, and fluxapyroxad caused down-regulated expression of hexokinase and 6-phosphate fructokinase but up-regulated the expression of pyruvate kinase. Strangely, the relative expression of 6-phosphate fructokinase increased when treated with benzovindiflupyr, and the changes in the relative expression of the other two genes were consistent with the above treatment (Figure 3). Hexokinase and 6-phosphate fructokinase are the rate-limiting enzymes in the glycolysis pathway. The results demonstrate that these five SDHIs fungicides can effectively inhibit the glycolysis pathway of F. asiaticum.

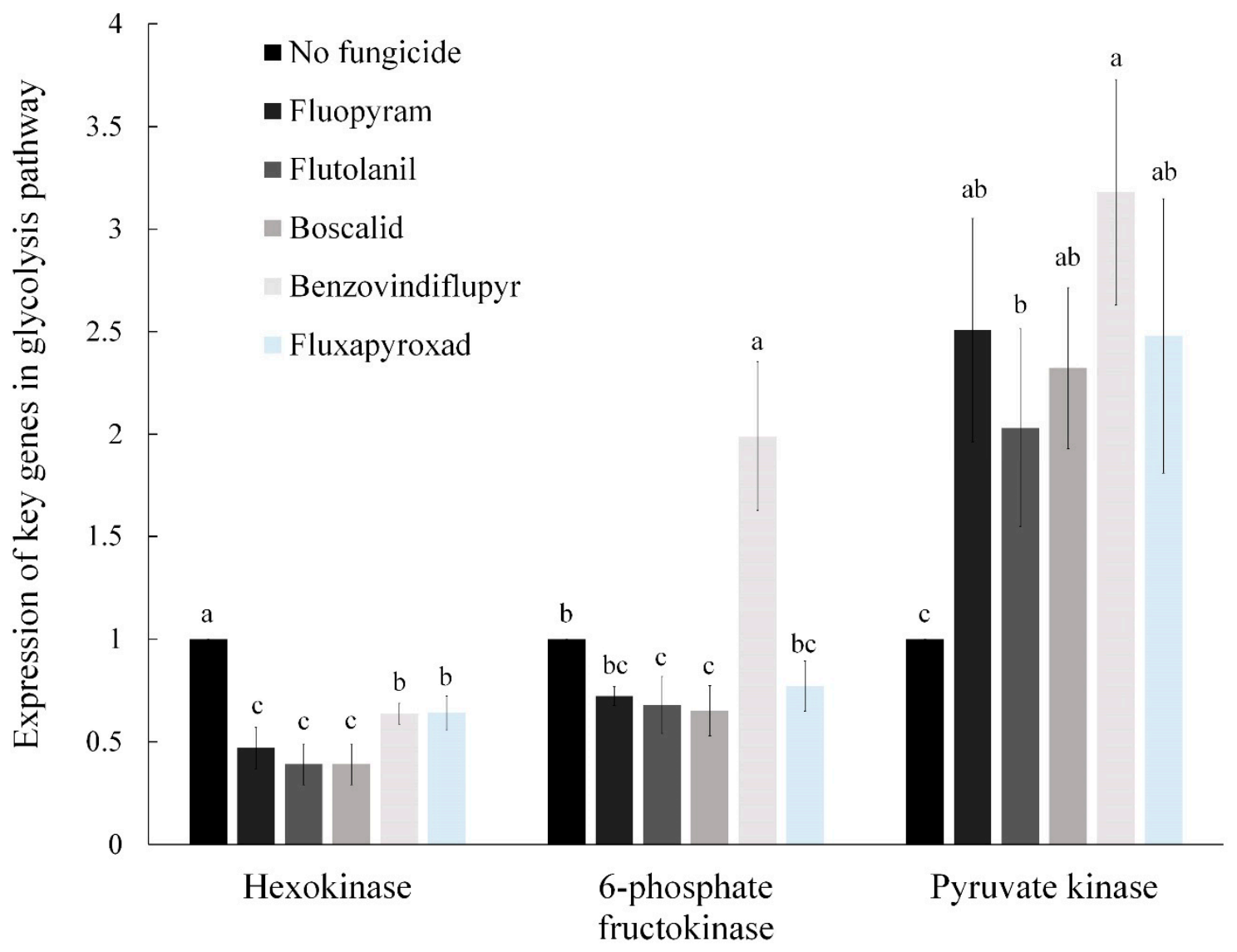

Figure 3. Relative expression levels of three key genes (hexokinase, 6-phosphate fructokinase, and pyruvate kinase) in the glycolysis pathway of the wild-type strain 2021 as affected by the five SDHIs. The final concentrations were $0.54 \mu \mathrm{g} / \mathrm{mL}$ for fluopyram, $2.96 \mu \mathrm{g} / \mathrm{mL}$ for flutolanil, $1.52 \mu \mathrm{g} / \mathrm{mL}$ for boscalid, $1.79 \mu \mathrm{g} / \mathrm{mL}$ for benzovindiflupyr, and $3.16 \mu \mathrm{g} / \mathrm{mL}$ for fluxapyroxad, respectively. Values are means and standard errors of three replicates. Means with different letters are significantly different $(p<0.05$, ANOVA, LSD).

\subsection{Citric Acid Content}

Citric acid is the first product of the TCA cycle, and previous studies have shown that its accumulation inhibits glycolysis [22,23]. Therefore, we determined the content of citric acid of the strain 2021 after treatment. The results indicated that citric acid strongly increased in F. asiaticum strain 2021 treated with these five SDHIs (Figure 4A). 

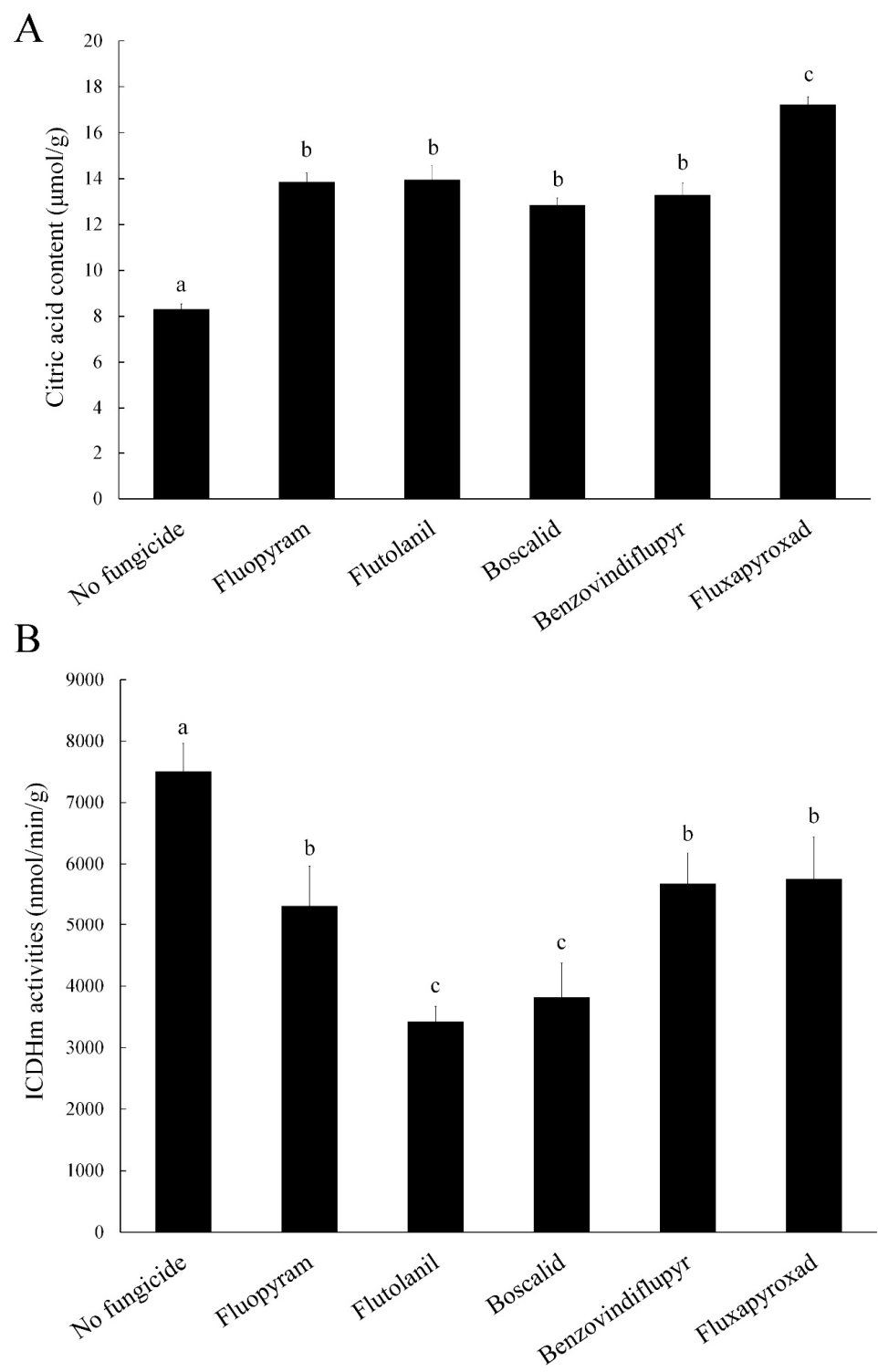

Figure 4. Impacts of the five SDHIs on citric acid content (A) and Isocitrate Dehydrogenase Mitochondrial (ICDHm) activities (B) in the wild-type strain 2021. The final concentrations were $0.54 \mu \mathrm{g} / \mathrm{mL}$ for fluopyram, $2.96 \mu \mathrm{g} / \mathrm{mL}$ for flutolanil, $1.52 \mu \mathrm{g} / \mathrm{mL}$ for boscalid, $1.79 \mu \mathrm{g} / \mathrm{mL}$ for benzovindiflupyr, and $3.16 \mu \mathrm{g} / \mathrm{mL}$ for fluxapyroxad, respectively. Values are means and standard errors of three replicates. Means with different letters are significantly different ( $p<0.05$, ANOVA, LSD).

\subsection{Isocitrate Dehydrogenase Mitochondrial (ICDHm) Activity}

ICDHm is the rate-limiting enzyme in the TCA cycle [24,25], and we are curious about the effects on the rate of the TCA cycle reaction under treatment of these five SDHIs. One unit of enzyme activity is defined as the production of $1 \mathrm{nmol}$ of NADH per gram of mycelium per minute. After treatment, the ICDHm activities of the strain 2021 were all significantly lower than that of the control (Figure 4B). These results indicate that SDHIs can effectively inhibit the rate of the TCA cycle of F. asiaticum.

\subsection{Succinate Dehydrogenase (SDH) and NADH Dehydrogenase Activities}

$\mathrm{NADH}$ dehydrogenase is an upstream complex of SDH, and we wondered what changes in NADH dehydrogenase would occur after inhibiting SDH activity. One unit of succinate dehydrogenase activity is defined as $1 \mathrm{nmol}$ of 2,6-dichlorophenol indophenol per gram of tissue per minute. One unit of NADH dehydrogenase activity is defined as the rate of decomposition of NADH. Treated with 
these five SDHIs, the succinate dehydrogenase activity of 2021 was significantly lower than that of the control (Figure 5A). However, the NADH dehydrogenase activity of 2021 was significantly higher than that of the control (Figure 5B). NADH dehydrogenase plays a role of catalyzing the transfer of two electrons from NADH to coenzyme $Q$ in the mitochondrial electron transport chain. The function of succinate dehydrogenase is to catalyze the transfer of electrons from succinic acid to FAD and iron-sulfur protein to coenzyme Q [14]. We surmised that after the treatment, the activity of succinate dehydrogenase is inhibited, and the transfer of electrons from succinic acid to coenzyme $Q$ is reduced. The strains are compensated for the loss of such electron transport, and thus there is an increase in the number of electrons transferred from NADH to coenzyme Q. The rate of consumption of NADH is accelerated, and the activity of NADH dehydrogenase is enhanced.

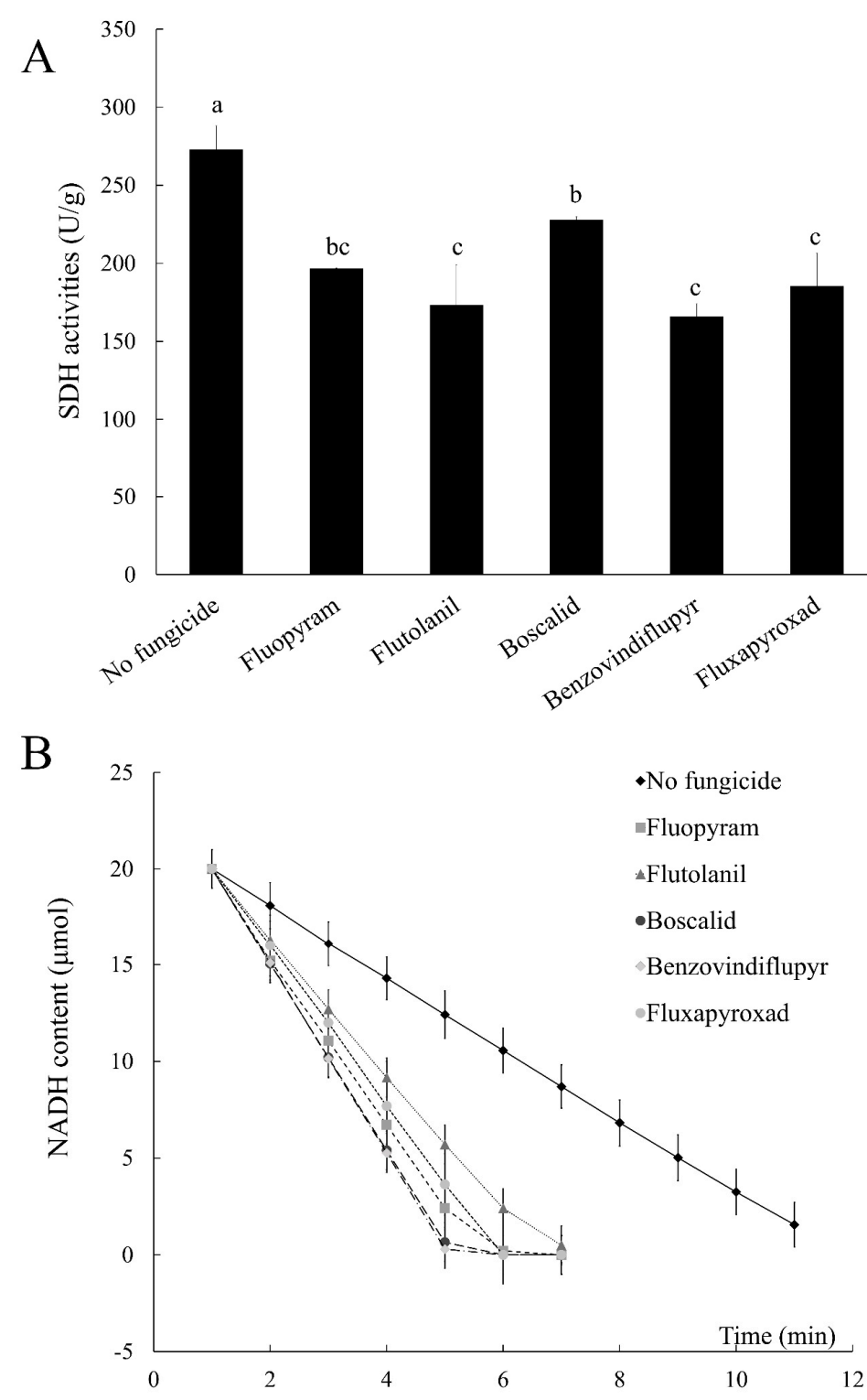

Figure 5. Impacts of the five SDHIs on SDH activities (A) and the rate of NADH decomposition (B) in the wild-type strain 2021. NADH dehydrogenase activity was defined as the rate of decomposition of $\mathrm{NADH}$. The faster the rate of decomposing NADH, the higher the activity of NADH dehydrogenase. The final concentrations were $0.54 \mu \mathrm{g} / \mathrm{mL}$ for fluopyram, $2.96 \mu \mathrm{g} / \mathrm{mL}$ for flutolanil, $1.52 \mu \mathrm{g} / \mathrm{mL}$ for boscalid, $1.79 \mu \mathrm{g} / \mathrm{mL}$ for benzovindiflupyr, and $3.16 \mu \mathrm{g} / \mathrm{mL}$ for fluxapyroxad, respectively. Values are means and standard errors of three replicates. Means with different letters are significantly different $(p<0.05$, ANOVA, LSD). 


\subsection{ATP Content}

SDHI fungicides are respiratory inhibitors that effectively inhibit the synthesis of energy in the strain, so we measured the ATP production in 2021 after treatment. It is unclear whether the content of ATP has an effect on the biosynthesis of DON. The quantification data indicated that ATP production in 2021 decreased after treatment compared to the control (Figure 6). The results showed that the energy metabolism in F. asiaticum can be affected when treated with these five SDHIs.

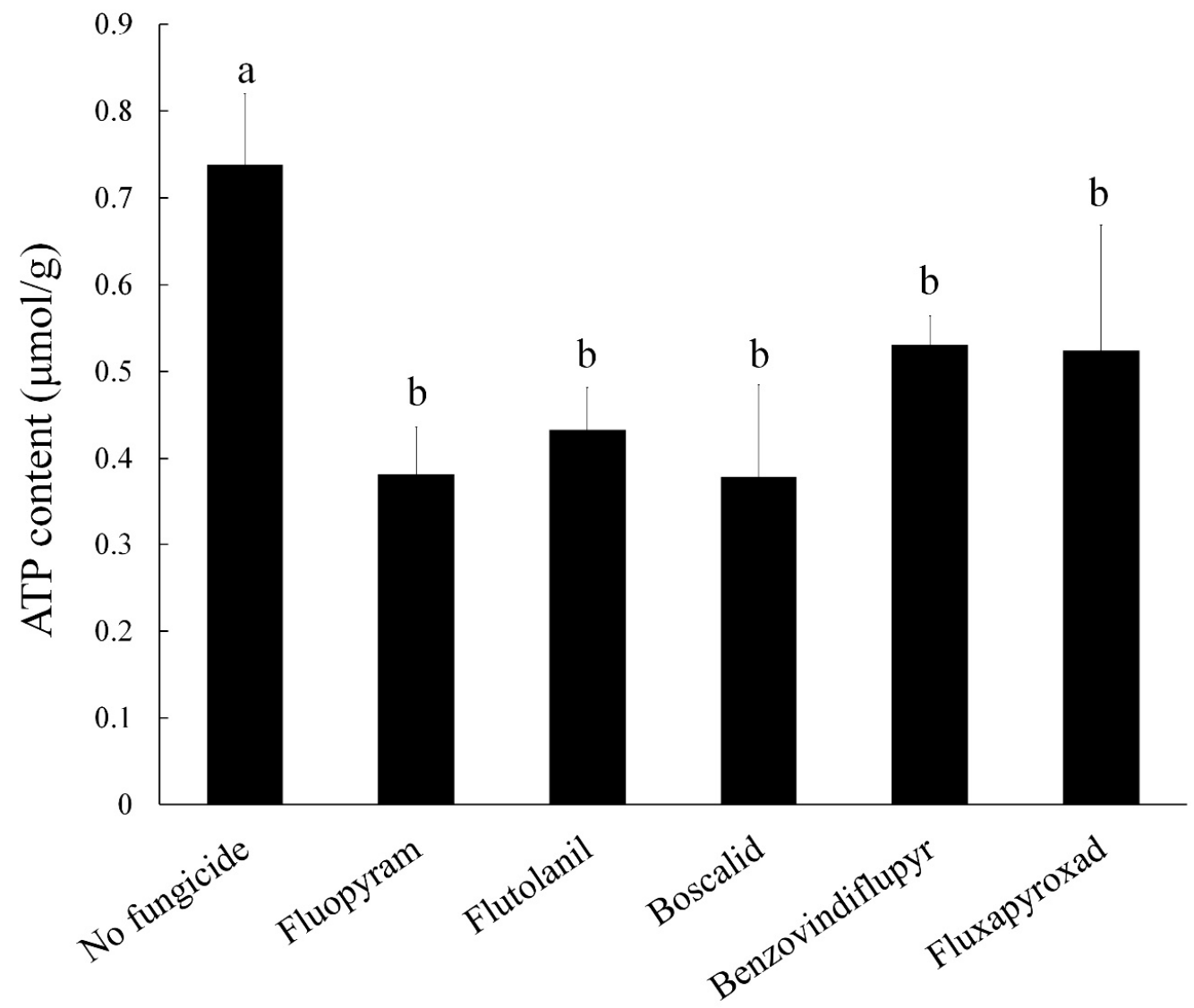

Figure 6. Impacts of the five SDHIs on ATP content in the wild-type strain 2021. The final concentrations were $0.54 \mu \mathrm{g} / \mathrm{mL}$ for fluopyram, $2.96 \mu \mathrm{g} / \mathrm{mL}$ for flutolanil, $1.52 \mu \mathrm{g} / \mathrm{mL}$ for boscalid, $1.79 \mu \mathrm{g} / \mathrm{mL}$ for benzovindiflupyr, and $3.16 \mu \mathrm{g} / \mathrm{mL}$ for fluxapyroxad, respectively. Values are means and standard errors of three replicates. Means with different letters are significantly different $(p<0.05$, ANOVA, LSD).

\subsection{Impact on Toxisomes}

Toxisomes are special spherical structures formed by F. graminearum under the conditions of toxin production. A previous study showed that the TRI1 gene was localized to the toxisomes [26]. To further investigate the impact of five SDHIs in inhibiting the DON production of F. asiaticum, we labeled the GFP green fluorescent marker on the TRI1 gene in 2021 to observe the effect of the five SDHIs on the morphology of the toxisomes. After the 2021 labeled with TRI1-GFP was cultured for 3 days in GYEP, we successfully observed a similar toxisome structure. Under the treatment of these five SDHIs, we found that the structure of the toxisomes was destroyed and the fluorescence intensity was weakened (Figure 7). The results indicated that SDHIs can destroy the structure of toxisomes, causing a reduction in the DON biosynthesis of F. asiaticum. 


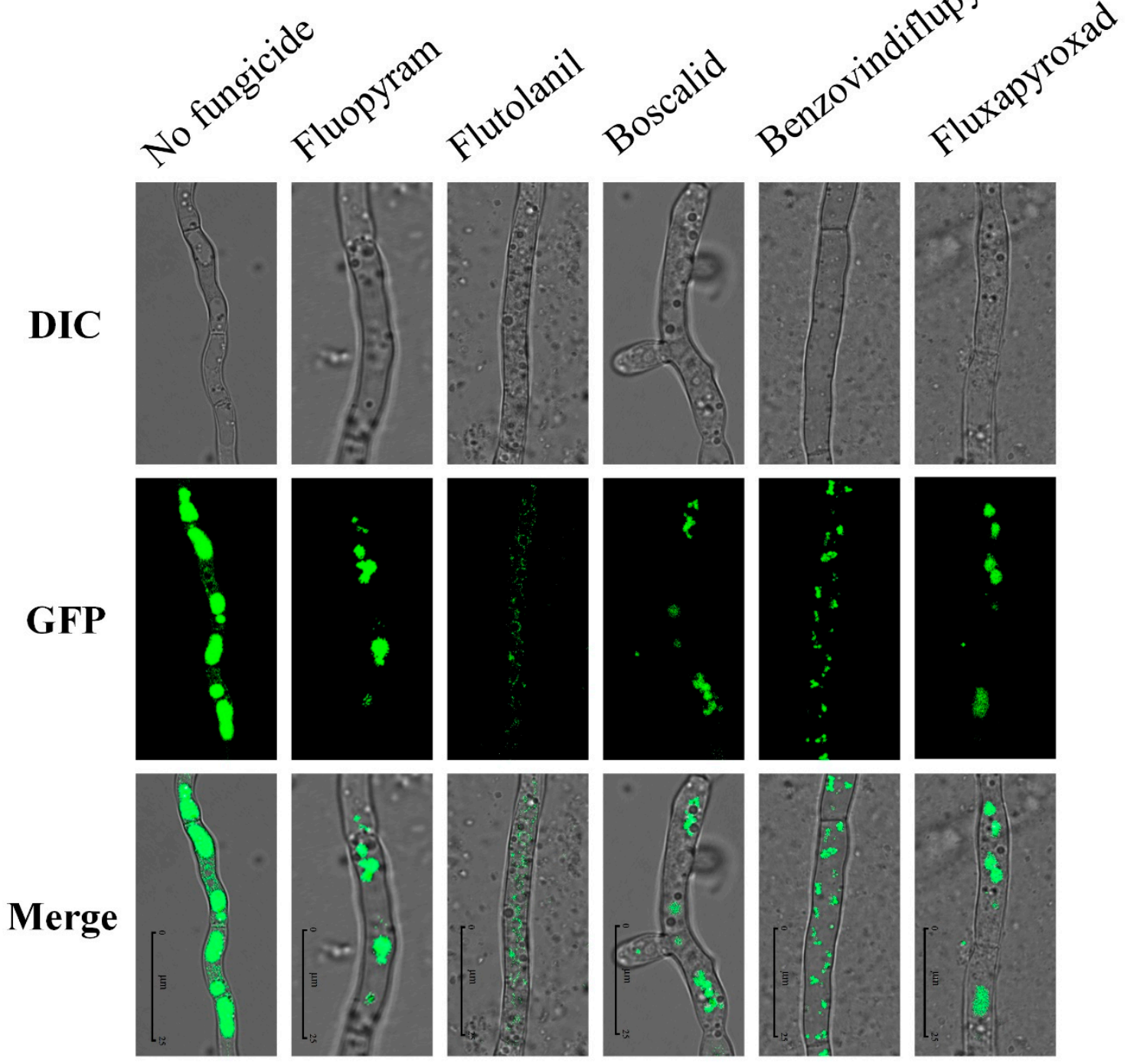

Figure 7. The morphology of the toxisomes in the wild-type strain 2021 as affected by the five SDHIs. The final concentrations were $0.54 \mu \mathrm{g} / \mathrm{mL}$ for fluopyram, $2.96 \mu \mathrm{g} / \mathrm{mL}$ for flutolanil, $1.52 \mu \mathrm{g} / \mathrm{mL}$ for boscalid, $1.79 \mu \mathrm{g} / \mathrm{mL}$ for benzovindiflupyr, and $3.16 \mu \mathrm{g} / \mathrm{mL}$ for fluxapyroxad, respectively. Bar $=25 \mu \mathrm{m}$. DIC: Differential interference contrast; GFP: Green fluorescence protein; Merge: Combination of DIC and GFP images. The pictures were captured under a $\times 100$ oil objective.

\section{Discussion}

FHB caused by FGSC is an economically important fungal disease on various cereals $[27,28]$. In addition to the loss of yield, the mycotoxins produced by FGSC in infected cereals pose a grave threat to the safety and health of humans and animals [4,5,29]. Since most wheat cultivars are susceptible to FGSC, the application of chemical fungicides has been a principal tool for controlling FHB in the last 40 decades. Previous studies have reported that the resistance of carbendazim is already widespread in China [8,9,30-35]. In addition, carbendazim can stimulate DON biosynthesis of FGSC, and carbendazim resistance can cause increase in DON production of FGSC $[28,36]$. A novel cyanoacrylate fungicide phenamacril exhibits a specific activity against Fusarium spp. and an inhibitory effect on DON production $[10,26]$. However, phenamacril has a high resistance risk in FGSC [10]. Previous studies have reported a strong correlation between FHB control efficacy and DON contamination [32,37-39]. Therefore, it is necessary to find novel fungicides for controlling FHB and DON contamination caused by FGSC. 
Succinic dehydrogenase inhibitors (SDHIs) studied in this paper are respiratory inhibitors. They inhibit the transmission of electrons from succinic acid to ubiquinone by completely or partially occupying the ubiquinone site of the substrate, thus hindering the energy metabolism of bacteria, inhibiting the growth of pathogens, and achieving the purpose of controlling diseases [12]. Currently, only one SDHI fungicide carboxin has been registered for the control of FHB in China. Previous studies reported that SDHIs have good effects in the prevention and control of other diseases. For example, pydiflumetofen can effectively inhibit Sclerotinia sclerotiorum, with an average $\mathrm{EC}_{50}$ value of $0.0250 \mu \mathrm{g} / \mathrm{mL}$ [18]. In addition, boscalid and isopyrazam have a better inhibitory effect on mycelial growth of Aspergillus flavus than Fusarium species. Meanwhile, boscalid can reduce the toxin contamination of $A$. flavus [40].

In China, FGSC mainly includes F. asiaticum and F. graminearum. In this study, the sensitivity of seven F. asiaticum and six F. graminearum strains to five SDHIs (fluopyram, flutolanil, boscalid, benzovindiflupyr, and fluxapyroxad) was determined. We found that the five SDHIs did not differ in inhibiting the mycelial growth of FGSC, except for fluopyram. However, these five SDHIs exhibited a higher activity in inhibiting spore germination than mycelial growth. The results showed that the five SDHIs have potential in controlling FHB caused by FGSC in the field. Additionally, fluopyram exhibited a better inhibitory effect on either mycelial growth or spore germination in comparison to the other four SDHIs. In addition to fungicidal activity, we also found that these SDHIs can decrease DON production in F. asiaticum in vitro. At present, the biosynthetic pathway of DON has been extensively studied, and nearly all DON biosynthesis-involved genes (TRI genes) have been identified [21,41,42]. The trichothecene precursor synthase gene TRI5 is a key enzyme in step one of DON biosynthesis [19]. In this study, five SDHIs caused a decrease in the TRI5 gene expression. Moreover, we also observed that the five SDHIs could disrupt the formation of the complete spherical structure of toxisomes in F. asiaticum. The results revealed that the five SDHIs not only exhibited an inhibitory effect on spore germination in FGSC, but can also decrease DON biosynthesis in F. asiaticum. Thus, the five SDHIs have a potential in either controlling FHB or reducing DON contamination in F. asiaticum-infected grains.

The pyruvic acid produced in glycolysis is first transported into the mitochondria and oxidatively decarboxylated under aerobic conditions to form acetyl-CoA [43]. Meanwhile, acetyl-CoA is the major substrate for the biosynthesis of a variety of secondary metabolites, including trichothecenes [19]. Therefore, the content of pyruvic acid and acetyl-CoA in the strain should be positively correlated with the content of DON. Previous studies have shown that the production of pyruvic acid controlled by hexokinase supplies the main substrate for the biosynthesis of many secondary metabolites, such as trichothecene, DON, fumonisins, penicillin, and aflatoxin [20]. As expected, the content of pyruvic acid and acetyl-CoA were significantly reduced as affected by the five SDHIs. Pyruvic acid is the final product of glycolysis, and the decrease in its content indicated that the five SDHIs inhibited the glycolysis pathway. To verify this hypothesis, we performed qRT-PCR analysis of three key genes in the glycolysis pathway. We found that the relative expression of hexokinase and 6-phosphate fructokinase significantly decreased, and the relative expression of pyruvate kinase was significantly increased after treatment with the five SDHIs, resulting in inhibition of the glycolysis pathway. However, the relative expression of 6-phosphate fructokinase increased after treatment with benzovindiflupyr, possibly due to other action sites of benzovindiflupyr. The up-regulation of pyruvate kinase may be due to the product activation caused by the decrease of pyruvic acid content.

SDHIs affect the activity of succinate dehydrogenase, catalyzing the oxidation of succinic acid to fumaric acid in the TCA cycle. Isocitrate dehydrogenase is the rate-limiting enzyme of the TCA cycle $[24,25]$. Therefore, we determined the citric acid content, isocitrate dehydrogenase, and succinate dehydrogenase activities to investigate the regulatory effect of the five SDHIs in the TCA cycle. We found that the five SDHIs inhibited succinate dehydrogenase and isocitrate dehydrogenase activities, causing the decrease of the TCA cycle. In addition, the five SDHIs caused increase in citric acid content. Citric acid is the product of the first step of the TCA cycle [22], and its accumulation is due to the inhibition of downstream reactions. In addition, the accumulation of citric acid inhibits 
the glycolysis pathway [23]. SDHIs are respiratory inhibitors, which inhibit energy metabolism in bacteria $[13,14]$. Therefore, out of curiosity on whether SDHIs have the same effect on F. asiaticum, we determined the ATP content of F. asiaticum treated with five SDHIs. As expected, the ATP content was significantly reduced.

In summary, these five SDHIs exhibited inhibitory effects on the spore germination of FGSC. Importantly, SDHIs can decrease DON biosynthesis in F. asiaticum in vitro. This may be attributed to the inhibitory effects on glycolysis, TCA cycle, and energy metabolism caused by SDHIs. Thus, the results of the study will provide valuable information for wheat protection programs against the toxigenic fungi responsible for FHB and the consequent DON contamination in wheat grains.

\section{Materials and Methods}

\subsection{Fungicides, Fungal Strains and Culture Conditions}

Technical-grade fluopyram, flutolanil, boscalid, benzovindiflupyr, and fluxapyroxad were kindly provided by Bayer (Shanghai, China), Nihon Nohyaku Co. (Shanghai, China), BASF (Shanghai, China), Syngenta (Beijing, China) and BASF (Shanghai, China), respectively. These fungicides were dissolved in methanol at $10 \mathrm{~g} / \mathrm{L}$ and stored at $4{ }^{\circ} \mathrm{C}$ prior to further use.

Thirteen FGSC strains were isolated from the infected wheat ears in the field and stored in the Fungicide Biology Laboratory, Nanjing Agricultural University (Nanjing, China). These strains were identified by PCR assay as previously described [44]. The strain 2021, BM-1, BM-4, BM-13, BM-14, BM-17 and BM-20 are identified as F. asiaticum, and the strains BM-2, BM-3, BM-5, BM-7, BM-9 and BM-10 are identified as F. graminearum. F. asiaticum is dominant in eastern China, the most serious region affected by FHB. In addition, the strain 2021 was isolated from the infected wheat ear in 2000, and its genome was sequenced and analyzed in our laboratory. Thus, the strain 2021, as an F. asiaticum model strain, was selected for further research in this study.

Potato dextrose agar (PDA, $200 \mathrm{~g} / \mathrm{L}$ potato, $20 \mathrm{~g} / \mathrm{L}$ glucose and $20 \mathrm{~g} / \mathrm{L}$ agar) was used for colony morphology examination and sensitivity test for five succinate dehydrogenase inhibitors in vitro. Water agar (WA, $16 \mathrm{~g} / \mathrm{L}$ agar) was used for the determination of spore germination [45]. Mung bean broth (MBB, $30 \mathrm{~g} / \mathrm{L}$ mung bean) was used for sporulation assays [46,47]. Yeast extract peptone dextrose medium (YEPD, $10 \mathrm{~g} / \mathrm{L}$ peptone, $20 \mathrm{~g} / \mathrm{L}$ glucose and $3 \mathrm{~g} / \mathrm{L}$ yeast extract) was used for conidial germination. Glucose yeast extract peptone medium (GYEP, $1 \mathrm{~g} / \mathrm{L}$ peptone, $50 \mathrm{~g} / \mathrm{L}$ glucose and $1 \mathrm{~g} / \mathrm{L}$ yeast extract) was employed for DON production.

\subsection{Fungicide Sensitivity Tests Based on Mycelial Growth and Spore Germination}

Prior to fungicide sensitivity tests, the preliminary experiments were performed to optimize fungicide concentration gradients. For fungicide sensitivity tests, at least five concentrations for each fungicide were determined, and inhibition rate for all fungicide concentrations ranged $10 \%$ to $90 \%$, and inhibition rate for medial concentration close to 50\%. For mycelial growth, PDA plates were amended with fluopyram to obtain final concentrations of $2.5,5,10,20$, and $40 \mu \mathrm{g} / \mathrm{mL}$ and amended with the other four SDHIs (flutolanil, boscalid, benzovindiflupyr, and fluxapyroxad) to obtain final concentrations of $31.25,62.5,125,250$, and $500 \mu \mathrm{g} / \mathrm{mL}$, respectively. Inverted mycelial plugs $(5 \mathrm{~mm}$ in diameter) cutting from the edge of an actively growing colony were transferred to $9 \mathrm{~cm}$ Petri dishes containing PDA media amended with the above described fungicide concentrations. Plates without fungicides were used as control. After incubation for 3 days in a growth chamber $\left(25^{\circ} \mathrm{C}\right)$, the colony diameters in two perpendicular directions for each PDA plate were measured and averaged. The $\mathrm{EC}_{50}$ values (effective concentration for 50\% inhibition of mycelial growth) were calculated with the probit regression of the percentage of inhibition against the logarithmic value of fungicide concentrations.

For spore germination, WA plates were amended with fluopyram to obtain final concentrations of $0.125,0.25,0.5,1$, and $2 \mu \mathrm{g} / \mathrm{mL}$ and amended with the other four SDHIs (flutolanil, boscalid, benzovindiflupyr, and fluxapyroxad) to obtain final concentrations of $0.5,1,2,4$, and $8 \mu \mathrm{g} / \mathrm{mL}$, 
respectively. Five mycelial plugs of each strain from the edge of 3-day-old colonies on PDA plates were transferred to a $50 \mathrm{~mL}$ flask containing $20 \mathrm{~mL}$ of mung bean broth. Conidia were filtered with two layers of lens wiping paper and collected by centrifuging at $5000 \mathrm{rpm}$ for $5 \mathrm{~min}$ after culturing at $25^{\circ} \mathrm{C}$ for 3 days in a shaker (175 rpm, $12 \mathrm{~h}$ of illumination every day). The conidia were suspended with sterile water, and the concentration was adjusted to $1 \times 10^{6} / \mathrm{mL}$. Then, $100 \mu \mathrm{L}$ of conidia suspension was spread on WA plate containing the above described fungicide concentrations. After incubation for $5-6 \mathrm{~h}$ at $25^{\circ} \mathrm{C}$ in the dark, the number of germinated conidia was measured. A conidium was considered germinated if the germ tube was at least half the length of the conidium. A total of 100 conidia were scored for each dish. The $\mathrm{EC}_{50}$ values (effective concentration for $50 \%$ inhibition of conidia germination) were estimated from the probit regression of the percentage of inhibition against the logarithmic value of fungicide concentrations [48]. Each concentration had three replicates, and the experiment was repeated twice.

\subsection{RNA Extraction and Reverse Transcription PCR}

The RNA simple Total RNA Kit (Tiangen, Beijing, China) was used to extract the total RNA from mycelia, and reverse transcription PCR was performed with the HiScript II qRT SuperMix for qPCR (+gDNA wiper) (Vazyme, Nanjing, China) as previously described [49]. The RNA integrity was validated by agarose gel electrophoresis and absorbance determination.

\subsection{DON Production and TRI5 Gene Expression}

For DON production, spore suspensions of the strain 2021 were prepared and diluted to $5 \times 10^{4} / \mathrm{mL}$. $1 \mathrm{~mL}$ of spore suspensions were added into 100mL GYEP [50,51]. After culturing in the dark at $28^{\circ} \mathrm{C}$ for $24 \mathrm{~h}$, the five SDHIs were added into the cultures and the final concentrations were $0.54 \mu \mathrm{g} / \mathrm{mL}$ for fluopyram, $2.96 \mu \mathrm{g} / \mathrm{mL}$ for flutolanil, $1.52 \mu \mathrm{g} / \mathrm{mL}$ for boscalid, $1.79 \mu \mathrm{g} / \mathrm{mL}$ for benzovindiflupyr, and $3.16 \mu \mathrm{g} / \mathrm{mL}$ for fluxapyroxad, respectively (the $\mathrm{EC}_{50}$ values are from the spore germination inhibition method and are listed in Table 2). After the incubation of an additive for 6 days, the culture liquid was collected and the mycelia were dried and weighed. DON production in the culture liquid was measured using the DON ELISA Kit (Wise, Zhenjiang, China) according to a previous study [7]. The DON ELISA Kit uses an indirect competitive ELISA method to detect the DON content in strains and cereals. Compared with the previous HPLC method, it is faster and easier to operate, while it also has higher detection accuracy. Its detection range is from $10 \mu \mathrm{g} / \mathrm{L}$ to $135 \mu \mathrm{g} / \mathrm{L}$. DON production ability in shake culture was expressed as the amount of DON produced per dry weight of mycelia $(\mu \mathrm{g} / \mathrm{g})$. The experiment was repeated three times independently, with each treatment having three replicates.

For TRI5 gene expression, the conidia of 2021 were added to GYEP $\left(5 \times 10^{4}\right.$ conidia per $100 \mathrm{~mL}$ GYEP). After culturing for $24 \mathrm{~h}$ at $28{ }^{\circ} \mathrm{C}$ in the dark, the concentrations of five SDHIs were then added to the cultures as described above. After the incubation of an additive for 2 days, mycelia were collected for extraction of total RNA as previously described. TRI5 gene expression was determined by qRT-PCR using the primers listed in Table 3, as described in Section 4.3. The experiment was repeated twice, with each treatment having three replicates.

Table 3. Primers used in this study.

\begin{tabular}{|c|c|c|}
\hline Primer & Sequence $\left(5^{\prime}-3^{\prime}\right)$ & Use \\
\hline FGSG_TRI5-qF & CACTTGTCAAGGAGCACTTTC & \multirow{2}{*}{$\begin{array}{l}\text { qRT-PCR for determining the expression of } \\
\text { TRI5 (FGSG_03537) }\end{array}$} \\
\hline FGSG_TRI5-qR & TGCTCAATCCAACATCCСТC & \\
\hline Actin-qF & ATCCACGTCACCACTTTCAA & \multirow{2}{*}{ qRT-PCR for inter-reference actin } \\
\hline Actin-qR & TGCTTGGAGATCCACATTTG & \\
\hline FGSG_00500-qF & CGACCTCCACGACAACA & \multirow{2}{*}{$\begin{array}{l}\text { qRT-PCR for determining the expression of } \\
\text { hexokinase (FGSG_00500) }\end{array}$} \\
\hline FGSG_00500-qR & GATAGCAGCAACGCCACA & \\
\hline
\end{tabular}


Table 3. Cont.

\begin{tabular}{|c|c|c|}
\hline Primer & Sequence $\left(5^{\prime}-3^{\prime}\right)$ & Use \\
\hline FGSG_09456-qF & GATAGATTGGAGAGCCGAGAGA & \multirow{2}{*}{$\begin{array}{l}\text { qRT-PCR for determining the expression of } \\
\text { 6-phosphate fructokinase (FGSG_09456) }\end{array}$} \\
\hline FGSG_09456-qR & GAGGTGCTGGATACACTTGATG & \\
\hline FGSG_07528-qF & GAGATCCGAACTGGTAAGACTC & \multirow{2}{*}{$\begin{array}{l}\text { qRT-PCR for determining the expression of } \\
\text { pyruvate kinase (FGSG_07528) }\end{array}$} \\
\hline FGSG_07528-qR & CGTCAGAAGCGGTAGCATAA & \\
\hline TRI1-GFP-F & $\begin{array}{l}\text { ACTCACTATAGGGCGAATTGGGTACT } \\
\text { CAAATTGGTTTTGTGAGTAGGCCTCATA }\end{array}$ & \multirow{2}{*}{$\begin{array}{c}\text { A pair of PCR primers to amplify } \\
\text { TRI1(FGSG_00071) fragments used for } \\
\text { construction of the TRI1-GFP, vector under } \\
\text { its own promoter }\end{array}$} \\
\hline TRI1-GFP-R & $\begin{array}{c}\text { CACCACCCCGGTGAACAGCT } \\
\text { CCTCGCCCTTGCTCACGTCATC } \\
\text { CTGTACCAATTCCAATCG }\end{array}$ & \\
\hline
\end{tabular}

\subsection{Expression of Key Genes in Glycolysis Pathway}

To determine the expression levels of key genes in glycolysis, the conidia of 2021 were added to YEPD $\left(1 \times 10^{5}\right.$ conidia per $100 \mathrm{~mL}$ YEPD). After culturing for $24 \mathrm{~h}$ at $25^{\circ} \mathrm{C}$, the concentrations of five SDHIs were added to the cultures as described above. After the incubation of an additive for 2 days, mycelia were collected for extraction of total RNA as previously described. The expression levels of key genes in glycolysis were determined by qRT-PCR with the primers listed in Table 3. All data were normalized to actin gene expression, and relative changes in gene expression levels were analyzed with the CFX Manager Software (3.1, Bio-Rad, Hercules, CA, USA), which automatically sets the baseline. The experiments were repeated three times, with each treatment having three replicates.

\subsection{Determination of Pyruvic acid, Acetyl-CoA, ATP and Citric Acid}

The conidial suspensions were added to YEPD $\left(1 \times 10^{5}\right.$ conidia per $100 \mathrm{~mL}$ YEPD $)$ and incubated for $24 \mathrm{~h}$, then the concentrations of five SDHIs were added to the cultures as described above. After incubation with an additive for 2 days, the mycelia were collected and used for the determination of pyruvic acid, acetyl-CoA, ATP, and citric acid. Pyruvic acid and acetyl-CoA were assayed using a pyruvic acid content test kit (Solarbio, BC2205, Beijing, China) and an acetyl-CoA content test kit (Solarbio, BC0980, Beijing, China), respectively. ATP and citric acid production were assayed using an ATP assay kit (Beyotime, S0026, Nanjing, China) and a citric acid content test kit (Solarbio, BC2150, Beijing, China), respectively. In short, $0.05 \mathrm{~g}$ of mycelia were added to the corresponding lysis buffer of different detection kits. After the lysis of mycelia, pyruvic acid, acetyl-CoA, ATP, or citric acid production were determined according to the manufacturer's instructions. The experiments were performed three times independently.

\subsection{SDH, ICDHm and NADH Dehydrogenase Activities}

The mycelia were collected as described in Section 4.6 and used for the activities of SDH and ICDHm. SDH and ICDHm activities were determined using a succinate dehydrogenase activity assay kit (Solarbio, BC0950, Beijing, China) and an isocitrate dehydrogenase mitochondrial activity assay kit (Solarbio, BC2160, Beijing, China), respectively. The experiments were performed three times independently, with each treatment having three replicates.

$\mathrm{NADH}$ dehydrogenase activity was defined as the rate of decomposition of NADH. This experiment reflects the change of NADH by measuring the change of absorbance at $340 \mathrm{~nm}[52,53]$. The mycelia were collected as described in Section 4.6. The mycelia $(0.05 \mathrm{~g})$ were ground with $1 \mathrm{~mL}$ of PBS phosphate buffer. The extracts were centrifuged for $10 \mathrm{~min}$ at $10,000 \mathrm{rpm}$ at $4{ }^{\circ} \mathrm{C}$, and the supernatant was ultrasonically broken. Finally, $100 \mu \mathrm{L}$ of NADH $(40 \mu \mathrm{mol})$ was added to $100 \mu \mathrm{L}$ supernatant, and the changes in absorbance at $340 \mathrm{~nm}$ for $15 \mathrm{~min}$ were recorded using a spectrophotometer. The experiments were performed three times independently, with each treatment having three replicates. 


\subsection{Microscopic Examinations}

In order to observe the morphological changes of the toxisomes, the strain 2021-TRI1-GFP labeled with TRI1-GFP was cultured in GYEP at $28^{\circ} \mathrm{C}$ for $24 \mathrm{~h}$, then the different concentrations of five SDHIs were added to the cultures as described above and cultured at $28{ }^{\circ} \mathrm{C}$ for $48 \mathrm{~h}$. All samples were mounted on glass slides and sealed with cover glasses. Images of toxisomes were obtained at room temperature using a LEICA TCS SP8 confocal laser-scanning microscope (LEICA, laser: At 488 nm). The experiment was performed three times independently.

\subsection{Statistical Analysis}

All the data in this study were analyzed with the SPSS 14.0 software (SPSS Inc. Chicago, IL, USA) to obtain statistical variances between repeated experiments. Fisher's LSD test $(p=0.05)$ was used to obtain the standard errors and determine whether there were significant differences among the biological characteristics.

Author Contributions: This study was conceived and designed by M.Z. and Y.D., C.X. organized and performed the experiments. M.L., Z.Z., C.X., D.C. and J.L. collated and analyzed the data. The manuscript was written by C.X. All authors read and approved the final manuscript.

Funding: This research was funded by the National Natural Science Foundation of China $(31772190,31572025)$.

Acknowledgments: This work was supported by the National Natural Science Foundation of China (31772190, 31572025).

Conflicts of Interest: The authors declare no conflict of interest.

\section{References}

1. O'Donnell, K.; Ward, T.J.; Aberra, D.; Kistler, H.C.; Aoki, T.; Orwig, N.; Kimura, M.; Bjornstad, S.; Klemsdal, S.S. Multilocus genotyping and molecular phylogenetics resolve a novel head blight pathogen within the Fusarium graminearum species complex from Ethiopia. Fungal Genet. Biol. 2008, 45, 1514-1522. [CrossRef] [PubMed]

2. Yli-Mattila, T.; Gagkaeva, T.; Ward, T.J.; Aoki, T.; Kistler, H.C.; O’Donnell, K. A novel Asian clade within the Fusarium graminearum species complex includes a newly discovered cereal head blight pathogen from the Russian Far East. Mycologia 2009, 101, 841-852. [CrossRef]

3. Zhang, H.; Theo, V.D.L.; Cees, W.; Chen, W.; Xu, J.; Xu, J.; Zhang, Y.; Feng, J. Population analysis of the Fusarium graminearum species complex from wheat in China show a shift to more aggressive isolates. PLoS ONE 2012, 7, e31722. [CrossRef] [PubMed]

4. Zhang, L.; Jia, X.; Chen, C.; Zhou, M. Characterization of carbendazim sensitivity and trichothecene chemotypes of Fusarium graminearum in Jiangsu province of China. Physiol. Mol. Plant Pathol. 2013, 84, 53-60. [CrossRef]

5. Tanaka, T.; Hasegawa, A.; Yamamoto, S.; Lee, U.S.; Sugiura, Y.; Ueno, Y. Worldwide contamination of cereals by the Fusarium mycotoxins nivalenol, deoxynivalenol, and zearalenone. 1. Survey of 19 countries. J. Agric. Food Chem. 1988, 36, 979-983. [CrossRef]

6. Goswami, R.S.; Kistler, H.C. Pathogenicity and in planta mycotoxin accumulation among members of the Fusarium graminearum species complex on wheat and rice. Phytopathology 2005, 95, 1397-1404. [CrossRef]

7. Li, J.; Duan, Y.; Bian, C.; Pan, X.; Yao, C.; Wang, J.; Zhou, M. Effects of validamycin in controlling Fusarium head blight caused by Fusarium graminearum: Inhibition of DON biosynthesis and induction of host resistance. Pestic. Biochem. Physiol. 2019, 153, 152-160. [CrossRef]

8. Chen, Y.; Wang, J.; Zhou, M.; Chen, C.; Yuan, S.K. Vegetative compatibility of Fusarium graminearum isolates and genetic study on their carbendazim-resistance recombination in China. Phytopathology 2007, 97, 1584. [CrossRef]

9. Duan, Y.; Zhang, X.; Ge, C.; Wang, Y.; Cao, J.; Jia, X.; Wang, J.; Zhou, M. Development and application of loop-mediated isothermal amplification for detection of the F167Y mutation of carbendazim-resistant isolates in Fusarium graminearum. Sci. Rep. 2014, 4, 7094. [CrossRef] [PubMed]

10. Chen, Y.; Wang, W.; Zhang, A.; Gu, C.; Zhou, M. Activity of the fungicide JS399-19 against Fusarium head blight of wheat and the risk of resistance. J. Integr. Agric. 2011, 10, 1906-1913. [CrossRef] 
11. Hgerhall, C. Succinate: Quinone oxidoreductases. Variations on a conserved theme. Biochim. Biophys. Acta-Bioenerget. 1997, 1320, 107-141. [CrossRef]

12. Kuhn, P.J. Mode of action of carboximides. Symp. Ser. Br. Mycol. Soc. 1984, 9, 155-183.

13. Keon, J.P.; White, G.A.; Hargreaves, J.A. Isolation, characterization and sequence of a gene conferring resistance to the systemic fungicide carboxin from the maize smut pathogen, Ustilago maydis. Curr. Genet. 1991, 19, 475-481. [CrossRef] [PubMed]

14. Ackrell, B.A. Progress in understanding structure-function relationships in respiratory chain complex II. FEBS Lett. 2000, 466, 1-5. [CrossRef]

15. Bardas, G.A.; Veloukas, T.; Koutita, O.; Karaoglanidis, G.S. Multiple resistance of Botrytis cinerea from kiwifruit to SDHIs, Qols and fungicides of other chemical groups. Pest Manag. Sci. 2010, 66, 967-973. [CrossRef]

16. Hervé, F.A.; Themis, J.M. Progress in understanding molecular mechanisms and evolution of resistance to succinate dehydrogenase inhibiting (SDHI) fungicides in phytopathogenic fungi. Crop Prot. 2010, 29, 643-651.

17. Zhou, M.; Ye, Z.; Liu, J. Progress of fungicide resistance. Nanjing Agric. Univ. 1994, 17, 33-41.

18. Duan, Y.; Xiu, Q.; Li, H.; Li, T.; Wang, J.; Zhou, M. Pharmacological characteristics and control efficacy of a novel SDHI fungicide pydiflumetofen against Sclerotinia sclerotiorum. Plant Dis. 2019, 103, 77-82. [CrossRef] [PubMed]

19. Alexander, N.J.; Proctor, R.H.; Mccormick, S.P. Genes, gene clusters, and biosynthesis of trichothecenes and fumonisins in fusarium. Journal of Toxicology. Toxin Rev. 2009, 28, 198-215. [CrossRef]

20. Zhang, L.; Li, B.; Zhang, Y.; Jia, X.; Zhou, M. Hexokinase plays a critical role in deoxynivalenol (DON) production and fungal development in Fusarium graminearum. Mol. Plant Pathol. 2015, 17, 16-28. [CrossRef]

21. Kimura, M.; Tokai, T.; Takahashi-Ando, N.; Ohsato, S.; Fujimura, M. Molecular and genetic studies of Fusarium trichothecene biosynthesis: Pathways, genes, and evolution. Biosci. Biotechnol. Biochem. 2007, 71, 2105-2123. [CrossRef] [PubMed]

22. Barnett, J.A.; Kornberg, H.L. The utilization by yeasts of acids of the tricarboxylic acid cycle. J. Gen. Microbiol. 1960, 23, 65-82. [CrossRef] [PubMed]

23. Halabe, B.A. The biological significance of cancer: Umitochondria as a cause of cancer and the inhibition of glycolytic with citrate as a cancer treatment. Med. Hypotheses 2007, 69, 826-828. [CrossRef] [PubMed]

24. Laporte, D.C.; Stueland, C.S.; Ikeda, T.P. Isocitrate dehydrogenase kinase/phosphatase. Biochimie 1989, 71, 1051-1057. [CrossRef]

25. Garnak, M.; Reeves, H.C. Phosphorylation of isocitrate dehydrogenase of Escherichia coli. Science 1979, 203, 1111-1112. [CrossRef]

26. Boenisch, M.J.; Broz, K.L.; Purvine, S.O.; Chrisler, W.B.; Nicora, C.D.; Connolly, L.R.; Freitag, M.; Baker, S.E.; Kistler, H.C. Structural reorganization of the fungal endoplasmic reticulum upon induction of mycotoxin biosynthesis. Sci. Rep. 2017, 7, 44296. [CrossRef] [PubMed]

27. Mcmullen, M.; Jones, R.; Gallenberg, D. Scab of wheat and barley: A re-emerging disease of devastating impact. Plant Dis. 1997, 81, 1340-1348. [CrossRef]

28. Parry, D.W.; Jenkinson, P.; Mcleod, L. Fusarium ear blight (scab) in small grain creals-A review. Plant Pathol. 1995, 44, 207-238. [CrossRef]

29. Zhang, Y.; Yu, J.; Zhang, Y.; Zhang, X.; Cheng, C.; Wang, J.; Hollomon, D.W.; Fan, P.S.; Zhou, M. Effect of carbendazim resistance on trichothecene production and aggressiveness of Fusarium graminearum. Mol. Plant Microbe Interact. 2009, 22, 1143-1150. [CrossRef]

30. Liu, S.; Duan, Y.; Ge, C.; Chen, C.; Zhou, M. Functional analysis of the $\beta_{2}$-tubulin gene of Fusarium graminearum and the $\beta$-tubulin gene of Botrytis cinerea by homologous replacement. Pest Manag. Sci. 2013, 69, 582-588. [CrossRef]

31. Yuan, S.; Zhou, M. A major gene for resistance to carbendazim, in field isolates of Gibberella zeae. Can. J. Plant Pathol. 2005, 27, 58-63. [CrossRef]

32. Duan, Y.; Xiao, X.; Li, T.; Chen, W.; Wang, J.; Fraaije, B.A.; Zhou, M. Impact of epoxiconazole on Fusarium head blight control, grain yield and deoxynivalenol accumulation in wheat. Pestic. Biochem. Phys. 2018, 152, 138-147. [CrossRef]

33. Duan, Y.; Yang, Y.; Li, T.; Zhao, D.; Cao, J.; Shi, Y.; Wang, J.; Zhou, M. Development of a rapid and high-throughput molecular method for detecting the F200Y mutant genotype in benzimidazole-resistant isolates of Fusarium asiaticum. Pest Manag. Sci. 2016, 72, 2128-2135. [CrossRef] 
34. Liu, S.; Che, Z.; Chen, G. Multiple-fungicide resistance to carbendazim, diethofencarb, procymidone, and pyrimethanil in field isolates of Botrytis cinerea from tomato in Henan Province, China. Crop Prot. 2016, 84, 56-61. [CrossRef]

35. Zhang, Y.; Xiao, Z.; Chen, C.; Zhou, M.; Wang, H. Effects of fungicides JS399-19, azoxystrobin, tebuconazloe, and carbendazim on the physiological and biochemical indices and grain yield of winter wheat. Pestic. Biochem. Phys. 2010, 98, 151-157. [CrossRef]

36. Chen, C.; Wang, J.; Luo, Q.; Yuan, S.; Zhou, M. Characterization and fitness of carbendazim-resistant strains of Fusarium graminearum (wheat scab). Pest Manag. Sci. 2007, 63, 1201-1207. [CrossRef]

37. Bai, G.; Plattner, R.; Desjardins, A.; Kolb, F.; Mcintosh, R.A. Resistance to Fusarium head blight and deoxynivalenol accumulation in wheat. Plant Breed. 2001, 120, 1-6. [CrossRef]

38. Haidukowski, M.; Pascale, M.; Perrone, G.; Pancaldi, D.; Campagna, C.; Visconti, A. Effect of fungicides on the development of Fusarium head blight, yield and deoxynivalenol accumulation in wheat inoculated under field conditions with Fusarium graminearum and Fusarium culmorum. J. Sci. Food Agric. 2005, 85, 191-198. [CrossRef]

39. Duan, Y.; Tao, X.; Zhao, H.; Xiao, X.; Li, M.; Wang, J.; Zhou, M. Activity of demethylation inhibitor fungicide metconazole on Chinese Fusarium graminearum species complex and its application in carbendazim-resistance management of Fusarium head blight in wheat. Plant Dis. 2019. [CrossRef]

40. Masiello, M.; Somma, S.; Ghionna, V.; Logrieco, A.F.; Moretti, A. In vitro and in field response of different fungicides against Aspergillus flavus and Fusarium species causing ear rot disease of maize. Toxins 2019, 11, 11. [CrossRef]

41. Desjardins, A.E.; Hohn, T.M.; McCormick, S.P. Trichothecene biosynthesis in Fusarium species-chemistry, genetics, and significance. Microbiol. Rev. 1993, 57, 595-604.

42. Kimura, M.; Anzai, H.; Yamaguchi, I. Microbial toxins in plant-pathogen interactions: Biosynthesis, resistance mechanisms, and significance. J. Gen. Appl. Microbiol. 2001, 47, 149-160. [CrossRef]

43. Cody, G.D.; Boctor, N.Z.; Filley, T.R.; Hazen, R.M.; Scott, J.H.; Sharma, A.; Yoder, H.S. Primordial carbonylated iron-sulfur compounds and the synthesis of pyruvate. Science 2000, 289, 1337-1340. [CrossRef]

44. Suga, H.; Karugia, G.W.; Ward, T.; Gale, L.R.; Tomimura, K.; Nakajima, T.; Miyasaka, A.; Koizumi, S.; Kageyama, K.; Hyakumachi, M. Molecular characterization of the Fusarium graminearum species complex in Japan. Phytopathology 2008, 98, 159-166. [CrossRef]

45. Liu, Y.; Liu, N.; Yin, Y.; Chen, Y.; Jiang, J.; Ma, Z. Histone H3K4 methylation regulates hyphal growth, secondary metabolism and multiple stress responses in Fusarium graminearum. Environ. Microbiol. 2015, 17, 4615-4630. [CrossRef]

46. Cappelli, R.A.; Peterson, J.L. Macroconidium formation in submerged cultures by a non-sporulating strain of Gibberella Zeae. Mycologia 1965, 57, 962.

47. Bai, G.; Shaner, G. Variation in Fusarium graminearum and cultivar resistance to wheat scab. Plant Dis. 1996, 80, 975. [CrossRef]

48. Qiu, J.; Xu, J.; Yu, J.; Bi, C.; Chen, C.; Zhou, M. Localisation of the benzimidazole fungicide binding site of Gibberella zeae $\beta 2$-tubulin studied by site-directed mutagenesis. Pest Manag. Sci. 2011, 67, 191-198. [CrossRef]

49. Zhou, Y.; Zhu, Y.; Li, Y.; Duan, Y.; Zhang, R.; Zhou, M. $\beta-1$ tubulin rather than b2 tubulin is the preferred binding target for carbendazim in Fusarium graminearum. Phytopathology 2016, 106, 978-985. [CrossRef]

50. Zheng, Z.; Gao, T.; Hou, Y.; Zhou, M. Involvement of the anucleate primary sterigmata protein FgApsB in vegetative differentiation, asexual development, nuclear migration, and virulence in Fusarium graminearum. FEMS Microbiol. Lett. 2013, 349, 88-98. [CrossRef]

51. Ji, F.; Xu, J.; Liu, X.; Yin, X.; Shi, J. Natural occurrence of deoxynivalenol and zearalenone in wheat from Jiangsu province, China. Food Chem. 2014, 157, 393-397. [CrossRef]

52. Okegbe, C.; Sakhtah, H.; Sekedat, M.D.; Price-Whelan, A.; Dietrich, L.E. Redox eustress: Roles for redox-active metabolites in bacterial signaling and behavior. Antioxid. Redox. Signal. 2012, 16, 658-667. [CrossRef]

53. Park, H.J.; Reiser, C.O.; Kondruweit, S.; Erdmann, H.; Schmid, R.D.; Sprinzl, M. Purification and characterization of a NADH oxidase from the thermophile thermus thermophilus HB8. Eur. J. Biochem. 1992, 205, 881-885. [CrossRef]

(C) 2019 by the authors. Licensee MDPI, Basel, Switzerland. This article is an open access article distributed under the terms and conditions of the Creative Commons Attribution (CC BY) license (http://creativecommons.org/licenses/by/4.0/). 